\title{
There are more asthmatics in homes with high cockroach infestation
}

\section{E. Sarinho $0^{1,2}$ D. Schor2, \\ M.A. Veloso ${ }^{2}$ and \\ J.A. Rizzo $0^{1,2}$}

\author{
${ }^{1}$ Centro de Pesquisas em Alergia e Imunologia Clínica em Pediatria, and \\ 2Departamento de Pediatria, Hospital de Clínicas, Faculdade de Medicina, \\ Universidade Federal de Pernambuco, Recife, PE, Brasil
}

\section{Correspondence \\ E. Sarinho \\ Av. Parnamirim, 327, Apto. 202 \\ 52060-000 Recife, PE \\ Brasil \\ Fax: +55-81-3441-4801 \\ E-mail: emanuelsarinho@uol.com.br}

Received November 22, 2002

Accepted January 5, 2004

\section{Abstract}

Although asthma has been commonly associated with sensitivity to cockroaches, a clear causal relationship between asthma, allergy to cockroaches and exposure levels has not been extensively investigated. The objective of the present study was to determine whether asthma occurs more frequently in children living in homes with high cockroach infestation. The intensity of household infestation was assessed by the number of dead insects after professional pesticide application. Children living in these houses in the metropolitan area of Recife, PE, were diagnosed as having asthma by means of a questionnaire based on the ISAAC study. All children had physician-diagnosed asthma and at least one acute exacerbation in the past year. Children of both sexes aged 4 to 12 years who had been living in the households for more than 2 years participated in this transverse study and had a good socioeconomic status. In the 172 houses studied, 79 children were considered to have been exposed to cockroaches and 93 not to have been exposed. Children living in residences with more than 5 dead cockroaches after pesticide application were considered to be at high infestation exposure. Asthma was diagnosed by the questionnaire in $31.6 \%(25 / 79)$ of the exposed group and in $11.8 \%(11 / 93)$ of the non-exposed group $(\mathrm{P}=0.001)$, with a prevalence ratio of 3.45 (95\% CI, 1.48-8.20). The present results indicate that exposure to cockroaches was significantly associated with asthma among the children studied and can be considered a risk factor for the disease. Blattella germanica and Periplaneta americana were the species found in $96 \%$ of the infested houses.

\section{Introduction}

Asthma is the most common childhood illness and is responsible for more than 350,000 hospital admissions annually, corresponding to the 4th most common cause for hospitalization in the Brazilian Public Health System (2.3\% of the total) and the 3rd
Key words

- Cockroaches

- Asthma

- Atopy

- Public health

- Plague control most common among children and young adults (1).

A multicenter study (International Study for Asthma and Allergies in Childhood, ISAAC) carried out in 56 countries demonstrated that the prevalence of asthma has been increasing throughout the world, with Brazil occupying 8th place, with a preva- 
lence of about $20 \%$ (2).

Mortality rates for asthma are low, but are increasing in magnitude in a number of countries and regions. Mortality rates in developing countries have been rising in the last ten years, corresponding to $5-10 \%$ of deaths by respiratory failure, with an elevated proportion of in-home deaths (1).

The traditional concept of asthma defines it as a complex syndrome characterized by a variable degree of obstruction of air flow, bronchial hyper-responsiveness and inflammation of the lungs as the result of genetic and environmental factors (3). It often begins in early childhood and is associated with atopy, a genetically determined predisposition toward producing $\operatorname{IgE}$ antibodies against common environmental allergens (4).

Exposure to allergens is assumed to play an important role in asthma, as indicated by the following considerations: the association of asthma with sensitivity to common allergens in the home is strong and found in various parts of the world; an allergenic bronchial provocation induces both immediate and delayed bronchial responses in asthmatics; a decrease in the levels of exposure to allergens results in a reduction in bronchial hyperactivity (5).

Sensitivity to mites in household dust is considered to be the strongest risk factor for asthma in some studies (6), but other allergens have also been demonstrated to be significantly related to asthma, such as dog and cat epithelium, mold spores and cockroaches $(7,8)$.

Allergy to cockroaches has been recognized for more than thirty years (9) and studies carried out throughout the world have shown an association between asthma and the development of specific IgE antibodies. In Brazil, the role of cockroach antigens in respiratory allergies has only been studied in the last 5 years $(10,11)$. Various antigens from the two most common species in the Western World, Periplaneta americana and
Blattella germanica, have been identified and purified. The most important of these are the major and the secondary antigen from Blattella germanica (Bla g1 and Bla g2) and the major antigen from Periplaneta americana (Peral), with an extensive crossreaction between them. Prick test reactivity and blood $\operatorname{IgE}$ response to roach antigens are demonstrable in many asthmatics. It has also been shown that an increase in lymphocyte proliferation in response to Bla g2 antigens is associated with high levels of Bla $g l$ or Bla g2 in homes (11).

A study carried out in 2002 at the Hospital das Clínicas of the Federal University of Pernambuco, demonstrated that allergic sensitivity to cockroaches was associated with asthma on the basis of both skin tests and specific serum IgE. These data suggest that exposure to insects is a possible risk factor for the illness (12).

Although the combination of cockroach allergy and exposure to high levels of infestation can explain some aspects of asthma among these patients, a clear causal relationship between these factors has not been sufficiently demonstrated $(13,14)$ and more information should be obtained about this relationship.

The objective of the present study was to determine if asthma occurs more frequently among children living in houses with high cockroach infestation and to identify the species of cockroaches most frequently found in the households studied.

\section{Material and Methods}

\section{Study design}

A cross-sectional study was carried out between September 2001 and July 2002 in residences with and without cockroach infestations and the presence of asthmatic and non-asthmatic children in these homes was also determined. The Ethics Committee of the Hospital das Clínicas of the Federal Uni- 
versity of Pernambuco reviewed and approved the protocol and the adults responsible for the children who participated in the study signed an informed consent form.

\section{Study population}

The study population consisted of children from residences within the metropolitan area of the city of Recife, PE, Brazil, whose parents or guardians had hired professional cockroach extermination services. The company serves $40 \%$ of the area market and accepted the invitation to participate in this study.

Based on the literature on exposure to cockroaches (12) and the asthma prevalence in the city (2), considering a discriminatory power of $80 \%$ between the two groups, with the level of significance set at $5 \%$ and a relative risk of the occurrence of an asthma episode to be 9.22 among those exposed (15), the minimum sample size for an association between exposure to cockroaches and asthma was calculated to be 108 children, 54 of them exposed to cockroaches and 54 not exposed.

Inclusion criteria were: age between 4 and 12 years, having lived in the residence for more than 2 years, and absence of diagnosed heart or respiratory diseases known by parents or guardians.

Children were excluded from the study if parents or guardians did not give consent to participate and also when the pest control technician observed visible molds on the walls or ceiling of the residence, in order to reduce the confounding effect of a probable high exposure to mold antigens or high humidity.

\section{Procedures}

An initial questionnaire was sent to each residence that solicited extermination services for cockroaches. We determined the presence of children in the household, their ages and if they had lived there for more than two years. A professional pest-control technician from the insect exterminating company, having previously been trained by two members of the research team, submitted the questionnaire to the parents or guardians. At that time, the technician verified the extent of cockroach infestation, as well as the species found, after application of the pesticide.

The extent of cockroach infestation was determined on the basis of direct evidence according to the semiquantitative criteria established by the extermination company, considering the number of cockroaches that died after the service: 0 to 5 - little or no infestation; 6 to 12 - moderate infestation, and more than 12 - high infestation. This criterion is an empirical and tentative one since there are no data about the correlation of the number of cockroaches in a house with the burden of antigen present.

The residences willing to participate in the study were selected from the data supplied by the questionnaires in chronological order of entry, according to the previously established inclusion criteria. Their inclusion was based on the solicitation of the insect exterminating service and not on the company files and those that requested the service more than once a year were excluded.

All the residences were middle/upperclass and presented a homogeneous pattern of hygiene. For each residence, only one child was selected. When more than one child lived in the house, the youngest within the age range of 4 to 12 years who had lived there for more than 2 years was selected. This was done because the influence of the environment seems to be more important as a determinant factor for asthma among younger children, when the immune system is still developing.

The insecticide was a deltametrine preparation applied in gel or liquid form that leaves no volatile residues. A Medline review of papers published during the last ten years showed no reports of association of this 
product with asthma. Indeed, the same product has been used for years for topical treatment of pediculosis and scabies in children, even in those with asthma.

Once the residences were selected, a member of the research team, blind to the results of infestation, applied a new questionnaire to the parents or guardians by telephone. The objective of this questionnaire, based on the ISAAC study (2), was to establish the diagnosis of asthma. When the diagnosis was positive, complementary questions were asked to assess the severity of the illness according to the criteria for asthma severity of the II Brazilian Consensus on Asthma Management (16). The specific ISAAC questionnaire for rhinitis was not applied in order to reduce the length of the telephone interview and thus reduce the chances of error in the answers.

\section{Statistical analysis}

The information gathered was coded and double entries were made and stored in a data bank constructed using the Epi-Info (version 6.0) statistical software. A descriptive analysis was later carried out to determine the frequency of gender and age variables, followed by an analysis to determine possible associations between asthma and the levels of exposure to cockroaches. Contingency tables were organized. The prevalence ratio with the $95 \%$ confidence interval was calculated as done for case-control studies.

For the purposes of statistical analysis, children in whose houses up to 5 dead cockroaches were observed after insecticide application were considered to be non-exposed, and children in whose houses more than 5 dead cockroaches were found after insecticide application were considered to be exposed to high infestation. This cut-off was chosen empirically once it was possible to identify a group of houses with less than this number of dead insects after extermination and another group with higher number of dead insects, usually more than 50 , after the insecticide application.

\section{Results}

A total of 181 children whose residences were submitted to cockroach extermination were eligible for the study. All were from middle or high social class families. Nine of the responsible adults chose not to participate. Of the 172 subjects who answered the ISAAC questionnaire, $45.9 \%$ (79/172) were exposed to high or moderate cockroach infestation (exposed group) and 54.1\% (93/ 172) were not exposed (non-exposed group).

Of the exposed children, 37 were males and 42 were females; $45.6 \%(36 / 79)$ were 5 years of age or younger and $54.4 \%$ (43/79) were older than 5 years. Of the non-exposed children, 45 were males and 48 were females; $40.8 \%$ (38/93) were 5 years of age or younger and $59.2 \%$ (55/93) were older than 5 years. We initially stratified the children by age groups, i.e., older than 5 years and 5 years or younger, because children younger than 5 years are more subject to asthmatic episodes, mainly due to viral infections. However, analysis of the results revealed no statistically significant difference between the two age groups and age stratification was discontinued. There was also no statistically significant difference between genders.

Among the exposed children, 31.6\% (25/ 79) were asthmatic while in the non-exposed children only $11.8 \%$ (11/93) were asthmatic (prevalence ratio: 3.45 ; 95\%CI: 1.48-8.20), as shown in Table 1. Therefore, the exposed children living in homes with high cockroach infestation had asthma more frequently than non-exposed ones, with a statistically significant difference $(\mathrm{P}<0.001)$.

Although the number of patients was small for comparison, we found that among the exposed children, 64\% (16/25) had mild asthma and 36\% (9/25) moderate or severe asthma. Among those who were not exposed, 
$72.7 \%(8 / 11)$ had mild asthma and 27.3\% (3/ 11) moderate to severe asthma $(P=0.89)$. It was not possible to correlate the extent of infestation with the severity of the disease due to the small number of subjects.

Regarding the species found, we observed an infestation by Blattella germanica in $55.7 \%$ (44/79) of the residences, by Periplaneta americana in $26.6 \%$ (21/79), by Blattella germanica and Periplaneta americana together in $13.9 \%$ (11/79), and by Blattella orientalis in $3.8 \%$ (3/79). Regarding infestation, it is worth mentioning that in noninfested houses, usually no or up to 3 to 5 dead insects were observed after insecticide application but in those considered to be infested (more than 5 dead insects) usually more than 50 dead insects were observed after the application. Stratifying the exposure to cockroaches according to the original company classification (no/low, medium or high infestation) did not change our results.

\section{Discussion}

A number of hypotheses have been proposed in order to explain the increase in prevalence and morbidity of asthma in developed countries over the last two decades. These hypotheses include changes in lifestyle with individuals spending more time in closed environments and a consequent increase in exposure to household allergens (17). Asthma and other forms of allergic illnesses represent a significant public health problem (18). Cockroaches have been associated with asthma in a number of regions throughout the world. Brazilian studies have recently demonstrated that 40 to $55 \%$ of children and young adults with asthma and/or allergic rhinitis exhibit positive reactions to the skin test and/or specific IgE for cockroaches $(12,19)$.

The present study showed that when there was cockroach home infestation (more than 5 dead insects after pesticide), there was also a 3.45 higher frequency of asthma in the children than when there was no cockroach infestation, in agreement with data of studies which used different techniques for the assessment of exposure $(5,13)$.

Unfortunately, in contrast to the many controlled clinical studies that support the use of pharmacological treatment of asthma, there has been a relatively small amount of research devoted to the exposure to allergens and to the determination of whether removing or minimizing allergen exposure would be an important measure for controlling asthma (20). Even for dust mites, which have been the allergens most extensively studied, there is some uncertainty about whether environmental control measures would actually bring effective benefits to the control of asthma (21).

The population of the present study consisted of 172 children of both sexes aged 4 to 12 years, from families of fair socioeconomic conditions. Exposure is assumed to be more intense in lower socioeconomic strata, with a greater association with asthma. Despite the existence of an association between allergic respiratory diseases (including asthma and rhinitis) and exposure to cockroach antigens; 19), the present group of children was not investigated for the presence of rhinitis using the ISAAC questionnaire.

The household species of cockroaches spend large part of the time aggregated, hidden in dark and damp places. As a result,

Table 1. Relationship between children exposure to cockroaches within the residence and prevalence of asthma.

\begin{tabular}{llcc}
\hline & \multicolumn{3}{c}{ Asthma } \\
\cline { 2 - 4 } & \multicolumn{1}{c}{ Yes } & \multicolumn{1}{c}{ No } & Prevalence ratio $(95 \% \mathrm{Cl})$ \\
\hline Exposed & $25(31.6 \%)$ & $54(68.4 \%)$ & $3.45(1.48-8.20)$ \\
Non-exposed & $11(11.8 \%)$ & $82(88.2 \%)$ & 1 \\
Total & 36 & 136 &
\end{tabular}

More than 5 dead cockroaches were found in homes of children exposed to cockroaches after an insect extermination treatment and 5 or less in homes of nonexposed children. $95 \% \mathrm{Cl}=95 \%$ confidence interval. 
infestation is not often apparent to the dwellers. Gelber et al. (22) demonstrated that $20 \%$ of homes studied with no visible evidence of cockroach infestation exhibited levels of Bla $g 2$ in at least one of the rooms of the house. However, the originality of the present research lies in the attempt to examine the hypothesis that cockroach infestation by the visualization and counting of dead insects after the application of an insecticide may be related to the frequency of asthmatic children living in these houses. The insects leave their dens to die after the application of the venom, permitting an approximate count which is a simple way to estimate the extent of infestation that can be of clinical relevance. The purpose of the study was not to measure the levels of cockroach allergens present in the residences, but to quantitatively assess the presence of cockroaches. However, we realize now that it was an oversight not to have determined the number of dead cockroaches in each room of the house, a procedure that would have permitted us to correlate our data with those in the literature, as mentioned above.

Based on data reported in a study by the National Cooperative Inner-City Asthma Study (NCICAS) in the United States (23), Arruda et al. (14) reported that the combination of exposure and sensitivity to cockroach allergens is a risk factor for the severity of asthma in children. Analysis of the relationship between cockroach infestation and severity of the illness in the 36 asthmatic patients in the present study showed that there were 16 children with mild asthma and 9 with moderate and/or severe asthma in the infested residences, whereas in the residences with no infestation 8 children were classified as having mild asthma and just three as having moderate and/or severe asthma. Although there are studies correlating exposure to cockroach allergens with the severity of asthma $(14,24)$, statistical analysis of the present data revealed no significant correlation between level of infestation and severity of the illness $(\mathrm{P}=0.89)$. The small number of asthmatics may explain this result.

The species of cockroaches most commonly found in homes are Blattella germanica and Periplaneta americana (25). Potential cockroach allergens in household dust include whole bodies of dead insects, saliva, secretions, shed products and feces. Relevant allergens have been identified in the body and the feces of the insects (26), and differences in concentration suggest that the feces are the most important source of allergens (27). In the present study, the species most commonly found were Blattella germanica (44 homes) and Periplaneta americana (21 homes), which were both present in some residences (11 homes), followed by Periplaneta orientalis (3 homes).

The use of professionally applied pesticides is effective. However, a long-lasting removal of cockroaches is difficult. For complete extermination, the pesticide must be applied periodically to all rooms of the house, together with an adequate set of cleaning measures in an effort to prevent re-infestation. This would guarantee better control of the exposure to allergens, although recent studies have shown that a significant reduction in the levels of cockroach allergens is difficult, even when extermination is achieved (28).

There is a lack of knowledge on the part of the population about the relationship between exposure to cockroach allergens and allergic asthma. When questioned, the large majority of persons interviewed in the present study (including most parents of asthmatic children) stated that they knew nothing about this association.

Cross-sectional studies simultaneously describe the observation of exposure and outcomes. Consequently, this design cannot be used to determine a cause and effect relationship but it is possible to formulate the hypothesis that the visual presence of dead cockroaches within residences after extermination can be associated with a higher 
frequency of asthmatic children living in these households. This hypothesis should be tested by multivariate analysis in order to eliminate possible confounding factors and by using analytic designs (cohort and casecontrol studies). In the present study, Blattella germanica and Periplaneta americana alone or in combination were the species found in $96 \%$ of the infested houses, although Blattella orientalis was observed in 3 (4\%) of them.

We recommend further studies on the subject of exposure to cockroaches in other regions. We also recommend that parents and guardians of asthmatic children be alerted to the probable association between cockroaches and asthma, and, although total longlasting extermination is difficult, it is worth the effort to minimize infestation as part of the strategy of avoiding exposure to allergens of asthmatic children and children with rhinitis.

\section{References}

1. Consenso Brasileiro no Manejo da Asma, 3 (2002). Jornal de Pneumologia, 8: S1-S4.

2. The International Study of Asthma and Allergy in Childhood (ISAAC) (1998). Steering Committee - Worldwide variation in prevalence of asthma symptoms: The Intemational Study of Asthma and Allergy in Childhood (ISAAC). European Respiratory J ournal, 12: 315-355.

3. Busse WW \& Lemanske Jr RF (2001). Advances in immunology: asthma. New England J ournal of Medicine, 344: 350-362.

4. Larsen GL (1992). Asthma in children. New England J ournal of Medicine, 326: 1540-1545.

5. Platts-Mills TAE, Blumenthal $K$, Perzanowski $M \&$ Woodfolk JA (2000). Determinants of clinical allergic disease. The relevance of indoor allergens to the increase in asthma. American J ournal of Respiratory and Critical Care Medicine, 162 (Part 2): S128-S133.

6. Squillace SP, Sporik RB \& Rakes G (1997). Sensitization to dust mites as a dominant risk factor for asthma among adolescents living in central Virginia. Multiple regression analyses of a population-based study. American J oumal of Respiratory and Critical Care Medicine, 156: 1760-1764.

7. Platts-Mills TAE, Rakes G \& Heyman PW (2000). The relevance of allergen exposure to the development of asthma in childhood. J ournal of Allergy and Clinical Immunology, 105: S503-S508.

8. Platts-Mills TAE, Vervloet $D$, Thomas W, Aalberse RC \& Chapman MD (1997). Indoor allergens and asthma: Report of the Third International Workshop. J ournal of Allergy and Clinical Immunology, 100: S2-S24.

9. Bernton HS \& Brown H (1964) Insect allergy - preliminary studies of the cockroach. J oumal of Allergy, 35: 506-513.

10. Maia AAM, Croce J , Guimarães J H \& Lopes M (1996). Sensibilização alérgica à Blattella germanica (Insecta: Dyctyoptera) em pacientes com asma e rinite na cidade de São Paulo, Brasil. Revista Brasileira de Alergia e Imunopatologia, 19: 47-50.

11. Filho NAR, Faria L, Riedi CA \& Zulato S (1999). Sensibilização a baratas em crianças asmáticas: relação com a gravidade da doença. Revista Brasileira de Alergia e Imunopatologia, 22: 151-155.

12. Lopes MIL (2002). Sensibilização à Blattella germanica e à Periplaneta americana. Master's thesis, Universidade Federal de Pernambuco, Recife, PE, Brazil.

13. Arruda LK, Vailes LD, Platts-Mills TAE, Hayden ML \& Chapman MD (1997). Induction of IgE antibody responses by glutathione $S$ transferase from the German cockroach (Blattella gemanica). J oumal of
Biological Chemistry, 272: 20907-20912.

14. Arruda LK, Vailes LD, Ferriani VPL, Santos AB, Pomés A \& Chapman MD (2001). Cockroach allergens and asthma. J ournal of Allergy and Clinical Immunology, 107: 419-428.

15. Litonjua AA, Carey VJ, Burge HÁ, Weiss TS \& Gold DR (2001). Exposure to cockroach allergen in the home is associated with incident doctors-diagnosed asthma and recurrent wheezing. J ournal of Allergy and Clinical Immunology, 107: 41-47.

16. Pereira CAC \& Sole D (1999). Segundo Consenso Brasileiro no Manejo da Asma. Sociedade Brasileira de Pneumologia e Tisiologia, São Paulo, 75-77.

17. Romagnani $S$ (2000). The role of lymphocytes in allergic diseases. J oumal of Allergy and Clinical Immunology, 105: 399-408.

18. Call RS, Smith TF, Morris E, Chapman MD \& Platts-Mills TAE (1992). Risk factors for asthma in inner city children. J oumal of Pediatrics, 121: $82-86$

19. Santos $A B$, Chapman MD, Aalberse RC, Vailes LD, Ferriani VP, Oliver C, Rizzo MC, Naspitz CK \& Amuda LK (1999). Cockroach allergens and asthma in Brazil: identification of tropomyosin as a major allergen with potential cross-reactivity with mite and shrimps allergens. J oumal of Allergy and Clinical Immunology, 104: 329-337.

20. Peyton A \& Eggleston PA (2001). Clinical trials of allergen avoidance in established asthma. J ournal of Allergy and Clinical Immunology, 108: 685-687.

21. Gotzsche PC, J ohansen HK, Burr ML \& Hammarquist CH (2002). Dust mite control measures for asthma (Cochrane Review). In: The Cochrane Library. Issue 2, Update Software. Oxford, England.

22. Gelber LE, Seltzer LH, Bouzoukis J K, Pollart SM, Chapman MD \& Platts-Mills TAE (1993). Sensitization and exposure to indoor allergens as risk factors for asthma among patients presenting to hospital. American Review of Respiratory Disease, 147: 573-578.

23. Eggleston PA, Rosenstreich DL, Lynn H et al. (1998). Relationship of indoor allergen exposure to skin test sensitivity in inner-city children with asthma. J oumal of Allergy and Clinical Immunology, 102: 563-570.

24. Rosenstreich DL, Eggleston PA, Kattan M et al. (1997). The role of cockroach allergy and exposure to cockroach allergen in causing morbidity among inner-city children with asthma. New England J oumal of Medicine, 336: 1356-1363.

25. National Asthma Education and Prevention Program (1997). Expert Panel Report 2: Guidelines for the Diagnosis and Management of 
Asthma. NHI Publication, 97-4051. National Heart Lung and Blood Institute, Bethesda, MD, USA.

26. Musmand J J, Horner WE, Lopez M \& Lehrer SB (1995). Identification of important allergens in German cockroach extracts by sodium dodecylsulfate-polyacrylamide gel electrophoresis and Western blot analysis. J ournal of Allergy and Clinical Immunology, 95: 877-885.

27. Yun YY, Ko SH, Park JW, Lee IY, Ree HI \& Hong CS (2001). Comparison of allergenic components between German cockroach whole body and fecal extracts. Annals of Allergy, Asthma, and Immunology, 86: 551-556.

28. Gergen PJ, Mortimer KM, Eggleston PA et al. (1999). Results of the National Cooperative Inner-City Asthma Study (NCICAS) environmental intervention to reduce cockroach allergen exposure in innercity homes. J ournal of Allergy and Clinical Immunology, 103: 501506. 